Gut, 1977, 18, 897-902

\title{
Platelet function in fulminant hepatic failure and effect of charcoal haemoperfusion
}

\author{
M. J. WESton, P. G. LANGley, M. H. RUBin, M. A. HANid, P. MEllon, \\ AND ROGER WILLIAMS
}

From the Liver Unit, King's College Hospital and Medical School, Denmark Hill, London

SUMMARY In 34 patients with fulminant hepatic failure, platelets, in addition to being reduced in numbers, were smaller than those of healthy controls. In keeping with this, capillary bleeding times were significantly longer than could be accounted for by reduction in numbers alone. In a small group of these patients use of charcoal haemoperfusion for temporary liver support produced a doubling of the capillary bleeding time despite only a small drop in arterial platelet counts. This disproportionate prolongation of bleeding time was almost certainly caused by the loss of larger platelets in the charcoal columns during perfusion, as the mean median volume also fell during perfusion. Rises in screen filtration pressure of the blood leaving the columns were found during some perfusions and thought to be indicative of platelet aggregates. Release of vasoactive substances from platelets could account for the hypotension often found at this time.

Since the introduction of disposable columns containing polymer-coated charcoal, trials of charcoal haemoperfusion have been undertaken in fulminant hepatic failure (Gazzard et al., 1974), drug overdosage (Vale et al., 1975), and uraemia (Winchester, 1976). Although the initial results in fulminant hepatic failure were very encouraging, there has been a high frequency of hypotension later in the series associated with variable losses of circulating platelets (Weston and Williams, 1976). In this paper we report more detailed studies of platelet function in 34 patients with fulminant hepatic failure and the effects of charcoal haemoperfusion. In addition to the measurement of platelet numbers, platelet volumes, and capillary bleeding times, blood leaving the columns was examined for the presence of platelet aggregates. These have been found in other extracorporeal perfusion systems and may be associated with deleterious effects, including hypotension.

\section{Methods}

The cause of fulminant hepatic failure in the 34 patients investigated was acute virus hepatitis in 17 (five had HBsAg in the serum), paracetamol overdose in 13 , drug hypersensitivity in three, and one with

Received for publication 11 May 1977 halothane-associated hepatic necrosis. Thirty-three of the patients had deteriorated to grade IV encephalopathy by the time platelet studies were carried out. The remaining patient was rousable throughout (grade III).

Nineteen patients were treated by charcoal haemoperfusion with Smith \& Nephew columns containing $300 \mathrm{~g}$ activated charcoal with polymer (polyhema) coating (Gazzard et al., 1974). In 12 patients charcoal with a polymer coat amounting to $4 \%$ by weight was used, whereas in another four more lightly coated charcoal $(2 \%$ by weight $)$, which has been used to treat drug overdose (Vale $e t$ al., 1975), was employed. The remaining three patients were treated with both $4 \%$ and $2 \%$ columns on separate occasions. Just before perfusion, mucous heparin 5000 units was given through a Scribner shunt used for access to the circulation. Further doses were given to maintain Lee-White clotting times around 20 minutes. Perfusions were repeated daily where possible until death or recovery. Fifteen patients were not treated by charcoal haemoperfusion. In one instance the patient remained rousable and therefore did not meet the criteria for charcoal haemoperfusion which was assessed only in those in grade IV coma-that is, unrousable. The remaining 14 patients had unstable blood pressure and/or recent bleeding, usually from the gastrointestinal tract and this precluded the use of charcoal haemoperfusion. 
PLATELET FUNCTION AND CELLULAR

AGGREGATES

Blood samples for platelet studies were drawn by clean venepuncture with a 21 gauge needle and $2.5 \mathrm{ml}$ placed in an EDTA bottle. The initial samples before haemoperfusion were taken, before administration of heparin, from Scribner shunts which had been inserted in arm or leg for access to the circulation. Later, during haemoperfusion, samples were taken from rubber inserts in the blood lines leading into and out of the charcoal column and kept at room temperature. Platelet counts were measured by phase contrast microscopy (Brecher and Cronkite, 1950). In many instances the measurements were checked with a Coulter counter (Model ZF with $70 \mu$ aperture) and the correlation between the methods was close $(r=0.93, \mathrm{P}<0.001)$. In order to construct population curves based upon their volume, platelet counts with the Coulter counter were determined at successively larger thresholds as illustrated in Fig. 1 (Manucci and Sharp, 1967) within one and four hours of drawing blood to allow for changes in volume that occur in EDTA (O'Brien and Woodhouse, 1968). The median platelet volume of the sample-namely, that at which $50 \%$ of the platelets are larger and $50 \%$ smaller-was calculated to enable numerical comparison of different specimens.

Measurement of the capillary bleeding time was carried out with a stressed template technique (Mielke et al., 1969). This was taken as the average time for two cuts, each $9 \mathrm{~mm}$ long and $1 \mathrm{~mm}$ deep, made on the volar aspect of the forearm to stop bleeding while a venous pressure of $40 \mathrm{mmHg}$ was maintained with a blood pressure cuff. Readings greater than 30 minutes were not measured further.

Platelet counts were made between six and 12 hours of the onset of grade III or IV coma in all 34 patients, none of whom was uraemic. Median platelet volumes were measured in 22 of these 34 samples, and bleeding times were measured within the subsequent half an hour period in 25 of these patients.

It was possible to make simultaneous measurements of bleeding time and platelet count immediately before and after 13 perfusions with Smith and Nephew columns containing $4 \%$ coated charcoal. Median platelet volumes were measured during another eight perfusions. Measurements of platelet numbers and volume before and after perfusion were made on arterial blood from the Scribner shunt and during perfusion from blood drawn from rubber inserts in the lines leading blood to and from the charcoal column.

Results of platelet counts and volumes and bleeding times, expressed as mean values $\pm 1 \mathrm{SD}$, were

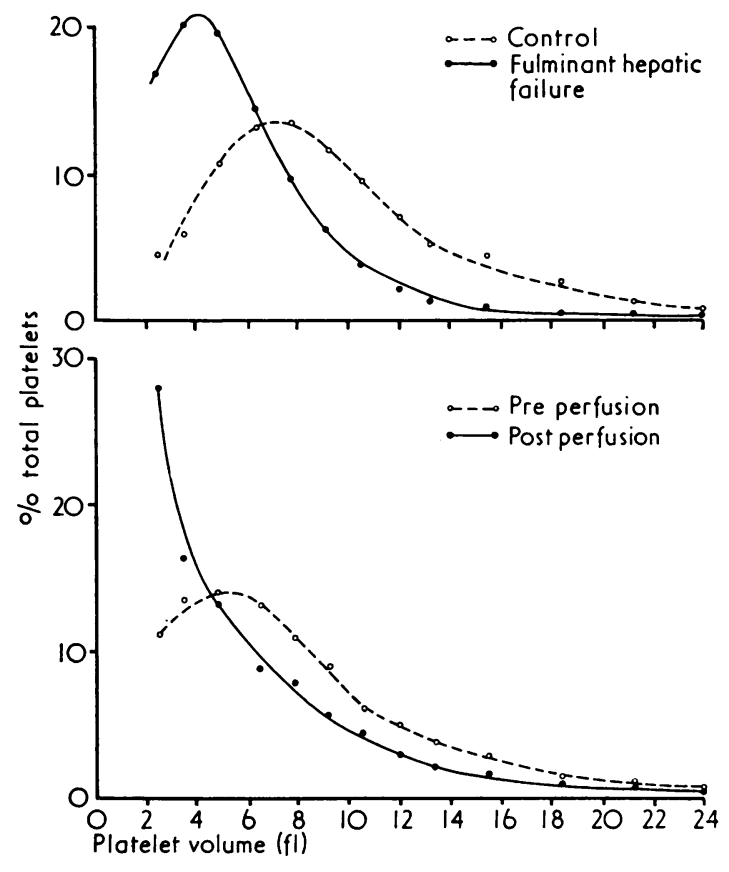

Fig. 1 Platelet population curves from a normal control and patient with fulminant hepatic failure (top) and showing effects of charcoal haemoperfusion (bottom).

compared with values in 54 healthy young adults, using Student's $t$ test.

To detect cellular aggregates aliquots of blood from the input and output lines of the column were pumped, within a minute of taking the sample, at $12.5 \mathrm{ml} / \mathrm{min}$ at room temperature through $1.8 \mathrm{~mm}$ diameter metal screen (20 $\mu$ thick) containing $20 \mu$ pores (Swank, 1968). The pressure generated within the syringe containing the aliquot of blood was recorded via a pressure transducer on a paper write-out. Tests were made on blood entering and leaving the column after 10 minutes of the start of the perfusion and thereafter at $\mathbf{3 0}$ minute intervals. If screen filtration pressure increased, the observations were repeated immediately, and because of the sometimes associated hypotension, the perfusion was discontinued.

\section{Results}

The mean platelet counts for the 34 patients were lower than those of the controls (157.1 \pm 91.5 compared with $\left.255.3 \pm 84.4 \times 10^{9} / 1, \mathrm{P}<0.005\right)$. Subsequent readings on the following days in three patients who were not treated by charcoal haemo- 
perfusion showed further reductions in the platelet count as the condition progressed. Platelet volumes were smaller than those of the controls, with mean median values of $5.91 \pm 0.99 \mathrm{fl}$ and $6.6 \pm 0.69 \mathrm{fl}$ respectively $(\mathrm{P}<0.005)$. This deficiency of large platelets is illustrated by the shift of the platelet population curves to the left (Fig. 1). As with platelet numbers, median platelet volumes decreased further during the course of the illness $(6 \cdot 14 \mathrm{fl}$ to $3.88 \mathrm{fl}$ and $6.56 \mathrm{fl}$ to $5.04 \mathrm{fl}$ ) in two cases not being treated by charcoal haemoperfusion. Changes of this magnitude were not seen in eight members of the control group who had estimations of platelet volume made on three different days (standard deviation $6 \%$, paired $t$ test).

Although platelet numbers were only modestly reduced initially, the capillary bleeding times showed a considerable prolongation compared with the controls $(17.7 \pm 9.6$ minutes and $6.96 \pm 1.6$ minutes respectively, $\mathrm{P}<0.001$ ). Five patients with platelet counts over $100 \times 10^{9} / 1$ had capillary bleeding times longer than 30 minutes.

The sequential changes in these measurements are illustrated by the patient who did not deteriorate beyond grade III encephalopathy and was therefore not treated by charcoal haemoperfusion (Fig. 2). During the initial phase of her illness, platelet numbers and median platelet volume decreased as she became more drowsy and her bleeding time became more prolonged. As her condition improved so did these various measurements.

EFFECTS OF CHARCOAL HAEMOPERFUSION Capillary bleeding times studied before and after 13 perfusions with $4 \%$ coated charcoal in eight patients showed a significant prolongation $(9 \cdot 8 \pm 1 \cdot 1$ to $19.8 \pm 2.4$ minutes, $P<0.005$, paired $t$ test).

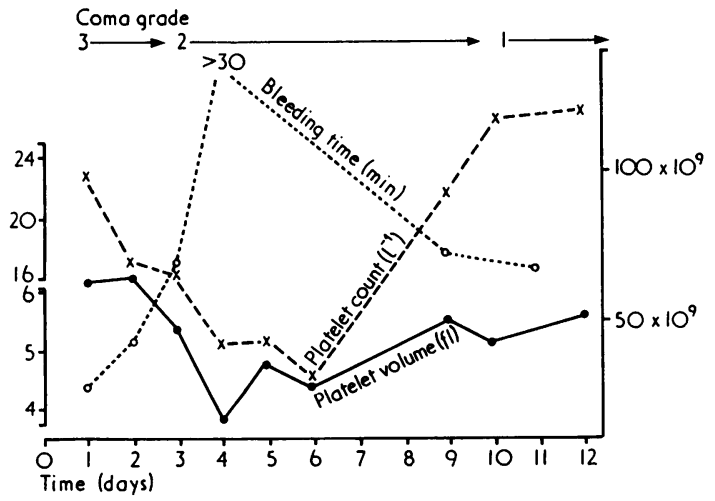

Fig. 2 Observations of platelet count and volume and capillary bleeding time made over a period of 12 days in a patient with fulminant hepatic failure caused by virus hepatitis.
After 12 of the perfusions the arterial platelet count fell but showed a small rise in the 13th $(154 \cdot 4 \pm 25$ to $124 \pm 24 \times 10^{9} / 1, \mathrm{P}<0.02$, paired $t$ test). In another seven perfusions with this column median platelet volumes fell in six and rose slightly in one $(6.4 \pm 0.73$ to $5.54 \pm 1.13, P<0.05$ paired $t$ test). Similar changes of platelet volume were found during haemoperfusion with $2 \%$ coated charcoal $(5 \cdot 31 \pm 1 \cdot 71$ to $4.35 \pm 2.23 \mathrm{fl}, \mathrm{n}=4, \mathrm{P}<0 \cdot 1$, paired $t$ test).

Platelet counts and volumes measured on blood entering and leaving the columns simultaneously showed that the extraction of platelets, both in numbers and size, was greatest during the first 30 minutes of perfusion, and then tended to diminish.

In those patients in whom measurements were repeated 24 hours later-that is, usually at the start of the next charcoal haemoperfusion-the platelet count had risen again in 17 instances, reaching the initial pre-perfusion level or more in seven. In another seven it remained the same as the postperfusion level or dropped further (mean value $24.6 \pm 5.7 \%$ lower than pre-perfusion count). Bleeding times were shorter than the post-perfusion reading in nine instances and showed no change in one but were longer than the initial pre-perfusion value (mean increase $27 \cdot 2 \pm 17 \cdot 3 \%$ ). Median platelet volumes recovered partially or completely from the post-perfusion value on six occasions but fell further in one (mean value $9 \cdot 1 \pm 4.9 \%$ lower than pre-perfusion value).

Seven of the patients treated by charcoal haemoperfusion recovered consciousness as did another three not so treated. However, of these 10, five succumbed later (four to infection and one to a cardiac arrest). The five long-term survivors recovered normal platelet function, but in the five who died initial improvements of platelet count and volume and bleeding time were not maintained.

DETECTION OF PLATELET AGgREGATES The screen filtration pressure test was applied to blood entering and leaving the columns during five perfusions with columns containing $4 \%$ polymer coated charcoal. Chronologically, this was at the time that the above effects on bleeding time, platelet count, and volume were documented. Only trivial changes in the screen filtration pressure were found and the test was not applied again until use of the more lightly coated ( $2 \%$ polymer) was introduced. Testing then showed that use of both the $2 \%$ or $4 \%$ polymer coated charcoal could cause screen filtration pressure to rise (Table).

The screen filtration pressure started to rise within 10 and 60 minutes of the start of the perfusion and repetition one to two minutes later showed steeper 
rises, often exceeding $200 \mathrm{mmHg}$ (Fig. 3). Blood entering the column never showed such changes. Perfusions were discontinued either because of the associated drop in the blood pressure (Table) or other possible harmful effects of the microembolisation of platelet aggregates. Two patients whose perfusions had been accompanied by a rise in screen filtration pressure were treated the following day without ill-effect. Reductions of arterial platelet counts were greater during perfusions during which the screen filtration pressure rose (Table).

Table Results of screen filtration pressure test

\begin{tabular}{|c|c|c|c|c|}
\hline $\begin{array}{l}\text { Case } \\
\text { number }\end{array}$ & & $\begin{array}{l}\text { Type of } \\
\text { column } \\
(\%)\end{array}$ & $\begin{array}{l}\text { Rise in screen } \\
\text { filtration } \\
\text { pressure }\end{array}$ & $\begin{array}{l}\text { Platelet } \\
\text { losses }\end{array}$ \\
\hline \multirow[t]{3}{*}{1} & First & 4 & No & 0 \\
\hline & Second & 4 & No & 19 \\
\hline & Third & 4 & No & - \\
\hline \multirow[t]{2}{*}{2} & First & 4 & No & 58 \\
\hline & Second & 4 & No & 13 \\
\hline \multirow[t]{2}{*}{3} & First & 2 & Yes & 75 \\
\hline & Second & 4 & No & - \\
\hline \multirow[t]{2}{*}{4} & First & $2^{*}$ & Yes & 66 \\
\hline & Second & 4 & No & - \\
\hline 5 & & 2 & Yes & 41 \\
\hline 6 & & 2 & No & 12 \\
\hline 7 & & $4^{*}$ & Yes & 65 \\
\hline 8 & & $4^{*}$ & Yes & 51 \\
\hline
\end{tabular}

* Perfusions during which blood pressure became unrecordable. Rises always exceeded maximum recording capacity of transducer ( $200 \mathrm{mmHg}$ ). Platelet losses are expressed as \% reduction of initial arterial count at end of perfusion

\section{Discussion}

Although thrombocytopenia is a well-recognised complication of fulminant hepatic failure (Clark et al., 1973), its association with platelets smaller than normal has not been reported previously. The degree of the thrombocytopenia, size of the platelets and length of the bleeding time depend, obviously, on the stage of the illness at which these are investigated (Fig. 2), and the measurements reported for the group as a whole were made relatively early in the illness. Patients with serum creatinine greater than $0.4 \mathrm{mmol} / \mathrm{l}$ were not studied because of the adverse effects of uraemia on platelet function (Lindsay et al., 1975). Although the platelet count was only slightly reduced compared with controls, the capillary bleeding times were over double the control values. Indeed, the five patients with capillary bleeding times over 30 minutes but platelet counts above $100 \times 10^{9} / 1$ would seem to have a considerable degree of platelet dysfunction. In normal subjects circulating platelets display heterogeneity of size, density, and metabolic function with the larger ones

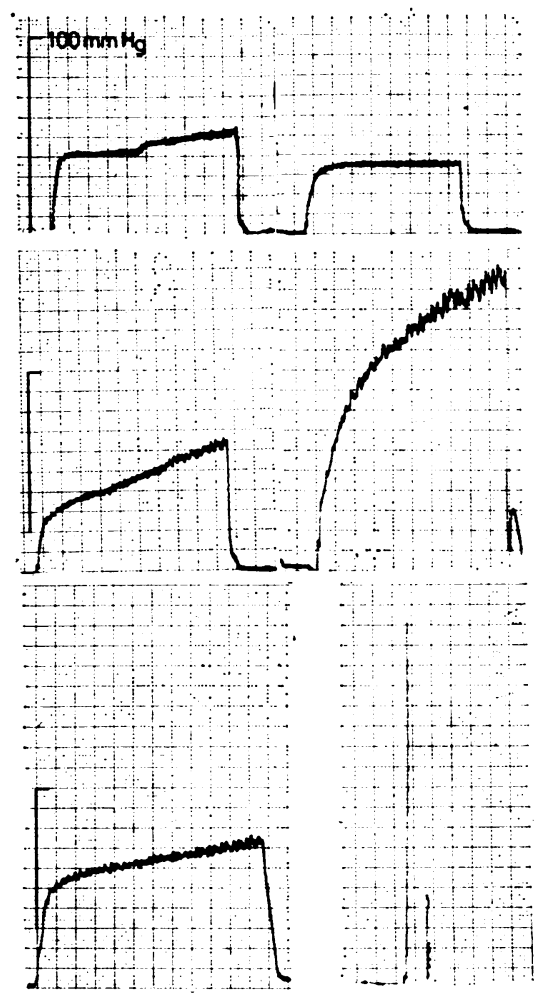

Fig. 3 Traces obtained with the screen filtration pressure test during charcoal haemoperfusion on aliquots of blood from the input line (left) and output lines (right) at 10 minutes (top), 25 minutes (middle), and 30 minutes (bottom).

showing greater metabolic activity (Karpatkin and Charmatz, 1969; Ginsburg and Aster, 1972). If these larger platelets are haemostatically the most active, then their selective deficiency in fulminant hepatic failure could explain the low platelet volumes found and the long capillary bleeding times. Conversely, patients with idiopathic thrombocytopenic purpura have short bleeding times (Harker and Slichter, 1972) and it is probable that capillary bleeding times reflect not the numbers of circulating platelets but their quality. In patients with acquired thrombocytopenia platelet volume may be an indirect measurement of this.

Disseminated intravascular coagulation, which is often present to a minor degree in fulminant hepatic failure (Rake et al., 1970), could explain both the thrombocytopenia and defect in platelet function, as fibrin(ogen) degradation products inhibit platelets (Kopec et al., 1968). However, platelets have recently been shown to be large in this condition (Hunt, 1976) and the levels of fibrin(ogen) degradation 
products bore little relationship to the bleeding time in our patients. The abnormalities of platelet number, platelet volume and bleeding time were similar whatever the aetiology of the syndrome, and probably reflect the severity of the hepatic necrosis. It is possible that a critical volume of functioning liver tissue is required for normal platelet production and release from the marrow, as Siemensma et al. (1975) have shown that partial hepatectomy in the rat is accompanied both by thrombocytopenia and changes in megakaryocytes.

The platelet function of the group of patients studied during charcoal haemoperfusion was, initially at least, better than the group as a whole as they had only slightly prolonged bleeding times and smaller platelets than controls. If, however, the drop of the platelet volume during perfusion is the result of a selective loss of large platelets in the charcoal column, an explanation is afforded for the doubling of the bleeding time after perfusion. Residual amounts of heparin after charcoal haemoperfusion were not measured but are very unlikely to exceed the levels shown by Borchgrevink (1961) to prolong the bleeding time. A similar mechanism could explain the platelet defect after use of other extracorporeal circuits (McKenna et al., 1975) and losses of large platelets have been reported after cardiopulmonary bypass (Laufer et al., 1975).

Potentially of a more serious nature than these changes during charcoal haemoperfusion is the rise in screen filtration pressure of blood leaving the column and the possible harmful effects of microembolisation and hypotension. The relatively large losses of platelets associated with the rise in screen filtration pressure and the fact that similar changes can be produced in blood by the addition of platelet aggregating agents implicates platelets in this phenomenon to a major degree.

More recently we have carried out a perfusion with a column containing $4 \%$ polymer coated charcoal during which heparin levels were monitored by protamine titration and thrombin clotting times and a particle filter (Pall Ultipore) across which the pressure gradient was monitored, was included in the circuit distal to the column. The patient had developed fulminant hepatic failure after an overdose of paracetamol and before perfusion her platelet count was $130 \times 10^{9} / 1$, median volume $5.52 \mathrm{fl}$, fibrinogen titre $130 \mathrm{mg} \%$, fibrinogen degradation product $4 \mu \mathrm{g} / \mathrm{ml}$, thrombin clotting time $28.7 \mathrm{~s}$, and antithrombin 3 level normal. The perfusion lasted 70 minutes. An initial bolus of 15000 units heparin maintained the thrombin clotting time greater than 120 seconds, with a heparin titration exceeding 4 units $/ \mathrm{ml}$ throughout the perfusion. This was uneventful for 50 minutes at which time the pressure gradient across the filter started to rise, as did the screen filtration pressure of the blood leaving the column. The filter failed to modify the screen filtration pressure and the patient's blood pressure, which had dropped from $100 / 50 \mathrm{mmHg}$ before perfusion to a systolic of $50 \mathrm{mmHg}$ transiently at the beginning of perfusion, dropped again to $70 \mathrm{mmHg}$ (systolic). Neither the rise in screen filtration pressure nor the pressure gradient across the filter itself was reversed by a further 10000 units of heparin and the platelet count dropped to $63 \times 10^{9} / 1$ and median volume to $4.48 \mathrm{fl}$.

Although the fibrin(ogen) degradation products rose to $64 \mu \mathrm{g} / \mathrm{ml}$, fibrinogen titre fell only to 128 $\mathrm{mg} / 100 \mathrm{ml}$ with no change in the reptilase time (60 seconds). The patient suffered a respiratory arrest and perfusion was therefore discontinued. Although the filter contained some white thrombus, the column itself contained no thrombus at all. Thus, deficiency of heparin with deposition of fibrin within the column and embolisation of fibrin particles does not seem to be the explanation for the rise in screen filtration pressure, but the process appeared to involve platelets primarily.

The close temporal relationship between rise in screen filtration pressure and fall in blood pressure suggests a cause and effect relationship, although this was not proven. Similar changes have been seen experimentally in dogs on oxygenators (Allardyce et al., 1966) and release of vasoactive material from platelets suspected as the cause of the hypotension. In order further to evaluate charcoal haemoperfusion in liver failure, more work is required to elucidate the nature of the rise in screen filtration pressure and to prevent its occurrence.

We are grateful to Dr P. N. Trewby for his assistance with the charcoal haemoperfusions and to Mrs Y. White for her help with some of the platelet studies.

\section{References}

Allardyce, D. B., Yoshida, S. H., and Ashmore, P. G. (1966). The importance of microembolism in the pathogenesis of organ dysfunction caused by prolonged use of the pump oxygenator. Journal of Thoracic and Cardiovascular Surgery, 52, 706-715.

Borchgrevink, C. F. (1961). The mechanism of the prolonged bleeding time provoked by dextran sulphate or by excessive doses of heparin. Acta Medica Scandinavica, 170, 365-373.

Brecher, G., and Cronkite, E. P. (1950). Morphology and enumeration of human blood platelets. Journal of Applied Physiology, 3, 365-377.

Clark, R., Rake, M. O., Flute, P. T., and Williams, R. (1973). Coagulation abnormalities in acute liver failure; pathogenetic and therapeutic implications. Scandinavian Journal of Gastroenterology, 8, suppl. 19, 63-70.

Gazzard, B. G., Weston, M. J., Murray-Lyon, I. M., Flax, H., Record, C. O., Portmann, B., Langley, P. G., Dunlop, E. H., Mellon, P. J., Ward, M. B., and Williams, R. 
(1974). Charcoal haemoperfusion in the treatment of fulminant hepatic failure. Lancet, 1, 1301-1307.

Ginsburg, A. D., and Aster, R. H. (1972). Changes associated with platelet aging. Thrombosis et Diathesis Haemorrhagica, 27, 407-415.

Harker, L. A., and Slichter, S. J. (1972). The bleeding time as a screening test for evaluation of platelet function. New England Journal of Medicine, 287, 155-159.

Hunt, F. A. (1976). A rapid method of assessing megathrombocytes-its application to thrombocytotic and acquired thrombocytopenic states. Pathology, 8, 47-55.

Karpatkin, S., and Charmatz, A. (1969). Heterogeneity of human platelets. Journal of Clinical Investigation, 48, 1073-1082.

Kopec, M., Wegrzynowiczy, Z., Budzynski, A. Z., Latallo, Z. S., Lipinski, B., and Kowalski, E. (1968). Interaction of fibrinogen degradation products (FDP) with platelets. Experimental Biology and Medicine, 3, 73-79.

Laufer, N., Merin, G., Grover, N. B., Pessachowicz, B., and Borman, J. B. (1975). The influence of cardiopulmonary bypass on the size of human platelets. Journal of Thoracic and Cardiovascular Surgery, 70, 727-731.

Lindsay, R. M., Moorthy, A. V., Koens, F., and Linton, A. L. (1975). Platelet function in dialyzed and non-dialyzed patients with chronic renal failure. Clinical Nephrology, 4, 52-57.

McKenna, R., Bachmann, F., Whittaker, B., Gilson, J. R., and Weinberg, M. (1975). The hemostatic mechanism after open heart surgery. Journal of Thoracic and Cardiovascular Surgery, 70, 298-308.
Mannucci, P. M., and Sharp, A. A. (1967). Platelet volume and shape in relation to aggregation and adhesion. British Journal of Haematology, 13, 604-617.

Mielke, C. H., Kaneshiro, M. M., Maher, I. A., Weiner, J. M., and Rapaport, S. I. (1969). The standardised normal Ivy bleeding time and its prolongation by aspirin. Blood, 34, 204-215.

O'Brien, J., and Woodhouse, M. A. (1968). Platelets: their size, shape, and stickiness in vitro-degranulation and propinguity. Experimental Biology and Medicine, 3, 90-97.

Rake, M. O., Pannell, G., Flute, P. T., and Williams, R. (1970). Intravascular coagulation in acute hepatic necrosis. Lancet, 1, 533-537.

Siemensma, N. P., Bathal, P. S., and Penington, D. G. (1975). The effect of massive liver resection on platelet kinetics in the rat. Journal of Laboratory and Clinical Medicine, 86, 817-833.

Swank, R. L. (1968). The screen filtration pressure method in platelet research. Significance and interpretation. Series Haematologica, 1, 146-167.

Vale, J. A., Rees, A. J., Widdop, B., and Goulding, R. (1975). Use of charcoal haemoperfusion in the management of severely poisoned patients. British Medical Journal, 1, 5-9.

Weston, M. J., and Williams, R. (1977). Extracorporeal detoxification. In Gastrointestinal Emergencies. Edited by F. Barany and A. Torsoli, 1976. Pergamon Press: Oxford.

Winchester, J. F., Apiliga, M. T., and Kennedy, A. C., (1976). Short term evaluation of charcoal haemoperfusion combined with dialysis in uraemic patients. Kidney International, 10, 5315. 